also be well to give more tenses and to distinguish more clearly those that have active from those that have middle or passive meaning. A quite intelligent student of Mr. Thompson's list might suppose that

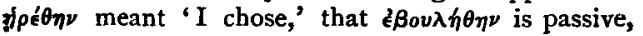
and that eyphropa is transitive. It is worth while to give plenty of space in order to make such things clear; in many places the English equivalent is necessary, for instance $\alpha \pi \epsilon \delta \delta \mu \eta \nu$.

To turn to the Syntax. The constructions that puzzle the beginner are those in which Greek differs from English and from Latin. He has first to grow

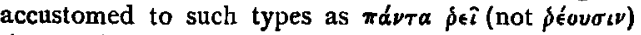

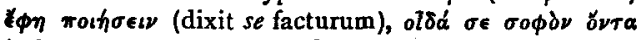

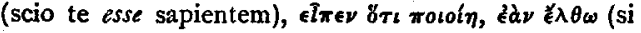
venero). On the other hand he does not need at first and cannot appreciate a systematic syntax, such as this, in which these new constructions are classified among a number of others, which, because they are found in English or Latin, present no difficulty to him. At a later stage such a study is useful. A clever boy who has worked at Greek for a year or two might learn much from Mr. Thompson's Syntax. But he will not always see the point that he is meant to see. In some places an example is necessary. - It

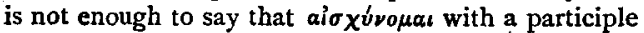
means 'I do it with shame' with the infinitive 'I do not do it for shame.' To bring home the difference one wants an instance, and the matter may be made clearer by comparing $\forall \delta \circ \mu a ! \pi o เ \hat{\nu} \nu$ with the first and

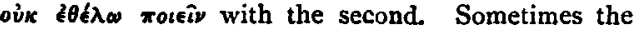
wording of the rules is not quite clear : for instance : The participle 'is used with $(a)$ verbs of perception, and verbs denoting $(b)$ the result of or $(c)$ the cause of perception.' Neither (b) nor (c) suggests the right class of verbs to the mind : the result of perception may, it is true, be knowledge. But it may also be emotion or action. The explanation of the uses of the cases, based to a great extent on Brugmann, is scarcely adapted to the understanding of the beginner. Such statements as: "The nominative denotes the central idea round which the action of the verb moves' or, 'The True Genitive denotes some kind of connection' belong to an advanced stage of the study of language. The uses of the True Genitive depending on nouns, adverbs, verbs are, as in Brugmann, treated separately. The consequence is that the partitive genitive, e.g., comes many times over,

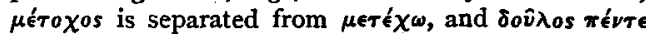

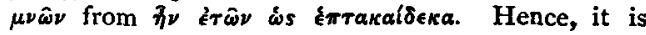
difficult to carry away any definite impression. The list of verbs taking the genitive will puzzle the student. It begins with $\dot{\varepsilon} \sigma \theta^{\prime} \omega$ (the difference between

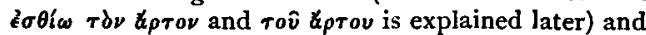
includes several such words as $\phi \theta 0 \nu \hat{\omega}$ without any example or note.

In conclusion I should like to suggest that we might with advantage draw a much sharper distinction between the elementary and the scientific grammar. The aim of the first should be purely practical ; only such words and forms should be included as the beginner is likely to meet fairly often (not $e . g ., \kappa \delta \rho \rho \eta$,

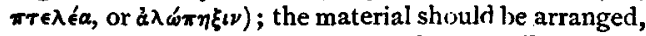
not as in the latest Historische Grammatik, but in the order in which it is most easy to assinilate. The scientific grammar is for those who have some knowledge of the language. Its aim is to classify the facts, to point out connections between them, to trace their history. It appeals to the reason rather than the memory.
W. E. P. Pantin.

\title{
CORRESPONDENCE
}

\author{
(To the Editor of The Classical Review.)
}

\section{SCHOOL EDITIONS AND THE TEACHING OF GREEK.}

\section{Dear Mr. EDItor,}

I am somewhat disturbed by the short shrift that you have given to certain School Editions of the Classics in the last number of the Review (p. 90). I have not had the pleasure of seeing all the seven books you comment on, but I have three of them by me at the present moment, and, whatever their faults or merits, it surprises me that you class them together as the same type of book. Of the late Dr. Shuckburgh's Herodotus $I V$. it can perhaps be said that it is a school bonk of 'the old type?' in the sense you mean. The way that the text is printed, with little English summaries written right across the page, e.g.

- To the North of the Argippaeans is a land unknown, of which,fabulous stories are told' does certainly suggest that the editor had beginners in his mind. None the less the book contains no short introduction to the dialect of Herodotus, which would be essential for a beginner, and the notes are rather adapted for the Sixth Form. For example

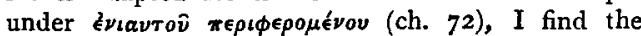

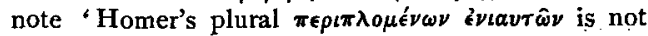
really parallel,' without further explanation. An allusive remark like this would be unintelligible unless one had already read a good deal of Homer.

While, however, it may be fairly urged that Dr. Shuckburgh had scarcely thought out the standard of his public, it appears to me that this is emphatically not true either of Mr. Marchant's Thucydides I., or of Mr. Ure's Selections from Thucydides VI. 'Mr. Marchant's books are definitely meant for Sixth Form Boys. The notes are not diffuse nor epidictic, but they are not meant for beginners. They give just the kind of help that a Sixth Form boy, or a good Pass man, or a Second or Third Class Honours man, needs. It seems therefore off the point to apply to this book your remark 'Notes of all sorts are jumbled up together, 
ome meant for very beginners, others for advanced tudents. There is no evidence that the editors now what are the needs of young boys, or how to neet them intelligently.'

When, however, I turn to Mr. Ure's book I am till more staggered by your criticism that it is a chool book of 'the old type." It is, on the whole, he most revolutionary book on Elementary. Greek hat I know. It is an experiment of 'the new eaching,' moving on parallel lines with your own 'First Greek Course,' Mr. Chambers's 'Greek War Jf Independence,' and Professor Walters's and my swn 'Forilegium Tironis Graecum.' It is from first sage to last meant for beginners, definitely, and -some old-fashioned people might think-even somically, meant for beginners. On p. 55 I find 'The article often preserves before $\mu \varepsilon^{\prime} \nu$ and $\delta \dot{\epsilon}$ its original use as a pronoun (cp. Eng. the=this, Fr. le=ille). You must always decide from the context whether the article before $\mu \epsilon^{\prime} \nu$ and $\delta \epsilon$ is used as a pronoun, as in this passage, or merely as the article, agreeing with some substantive that follows.' On p. 60 again $I$ read that "There are two negatives in Greek ov and $\mu \eta^{\prime}$; and I do not think there is a single remark in the book out of harmony with these true, but scarcely 'advanced' statements! The principles, too, on which $\mathrm{Mr}$. Ure has acted are fully explained in his Preface.

You will perhaps answer me, Mr. Editor, that Thucydides is not meant for ' young boys.' But why should you assume that all beginners are young boys? The book was written for the Matriculation Examination of the Northern Universities. Why should we only publish editions that assume that Greek is begun at the age of eleven, or even at that of fourteen? The whole tendency of the more advanced opinion on the teaching of Greek is that, even under favourable conditions, it had better be begun some years later than it is at present. You are yourself, of course, one of the chief exponents of this view. Even those, however, who are not convinced that this is the ideal to aim at, must allow that in a large number of boys schools, and in the majority of girls schools, arrangements are not in fact made for teaching Greek till towards the end of the school course. There are plenty of people, too, who want to learn Greek, and yet have no opportunity of being taught it at school at all, but have to teach it themselves with a little private help, so as to fit themselves for the younger Universities. I have had several hundreds of students in my Greek classes since $I$ have been at Cardiff--and the figures are not an exaggeration-who never began the Alphabet till they were I8, 19, or 20. A few of them have become very good scholars indeed, but-what is far more important - the great mass of them have taken a working knowledge of Greek and a love of Greek to many scattered pulpits, and many small secondary schools. This has probably happened on a bigger scale in Wales than elsewhere, because the Welsh temperament loves Greek poetry; but it is happening more or less all over the country. In the past, knowledge of Latin and Greek was a Class Distinction, and a Sex Distinction also. We hear from the great public schools that this is passing away, and that 'modern sides 'are increasing at a rapid rate. If this tendency were not counterbalanced in another direction there might be cause for alarm. What is really happening, however, is that the old Class and Sex Distinction is being replaced by a new and more natural line of Cleavage. Our aim now must be to enlist on the side of Greek all those who love poetry and value the spiritual side of things, all who want to know what is said in the greatest of the world's literatures. And we want books for them, not baby books, nor dull books, but the best things in Greek adapted for grownup beginners. We want Homer, and Plato, and Thucydides, and Aristophanes; and so long as the subject matter is great, and we are introduced to it by a good scholar, we shall listen to him with gratitude when he tells us that 'There are two negatives in Greek, ou and $\mu$ '́.'

\section{I am, dear Mr. Editor,}

RONALD BURROWS.

University College, Cardiff.

\section{LATIN READING IN SCHOOLS.}

SIR,

Might I, as one imperitiae obscuritate inuolutus, ask for enlightenment on some words of Prof. E. V. Arnold in his article on Latin and Politics (above, p. 67)? Already in more quarters than one the idea is gaining ground that the best Latin authors only .... must be selected .... so as to form a complete scheme of reading within the ordinary school course.'

I had thought that this was an idea against which the Classical Association would warn those who desire a 'quickening of the spirit and renewing of the methods of classical teaching,' exhorting them to an extension of the curriculum.

May I quote Lord Halsbury's words at the Second general meeting of the Classical Association January I905 (Proc. p. 35)? 'I do not mean to say that the jealous treatment of Greek literature in the sense that none but the best models shall be presented to the pupil's mind has not been too rigidly insisted on, and that there might well be a more diffused and more free intercourse with Greek writers, even if not the best specimens of Attic Greek. Few books are more amusing to a boy than Herodotus...... I have referred to Greek but it is only because the cry against Greek has been the loudest and most insistent. The narrowness of the Latin curriculum is still what one learns from those who have ceased tc take any interest in Latin literature. Horace and Virgil-Virgil and Horace. How many have read or heard of the Quaestiones Naturales of Seneca i And how many but for the exertions of Mr. Rowe and Mr. Justice Ridley would have read Lucan's Pharsalia ?'
G. A. Purton. 